\title{
Modified MAX Phase Synthesis for Environmentally Stable and Highly Conductive $\mathrm{Ti}_{3} \mathrm{C}_{2} \mathrm{MXene}$
}

\author{
Tyler S. Mathis ${ }^{\mathrm{a}}$, Kathleen Maleski ${ }^{\mathrm{a}}$, Adam Goad ${ }^{\mathrm{a}}$, Asia Sarycheva ${ }^{\mathrm{a}}$, Mark Anayee ${ }^{\mathrm{a}}$, Alexandre C. \\ Foucher $^{\mathrm{b}}$, Kanit Hantanasirisakula , Eric A. Stach ${ }^{\mathrm{b}, \mathrm{c}}$, Yury Gogotsi ${ }^{\mathrm{a},{ }^{*}}$ \\ ${ }^{a}$ A.J. Drexel Nanomaterials Institute and Department of Materials Science and Engineering, Drexel University, Phil- \\ adelphia, PA, USA \\ ${ }^{\mathrm{b}}$ Department of Materials Science and Engineering, University of Pennsylvania, Philadelphia, PA, USA \\ ${ }^{\mathrm{c}}$ Laboratory for Research on the Structure of Matter, University of Pennsylvania, Philadelphia, PA, USA
}

Keywords: MXene, $\mathrm{Ti}_{3} \mathrm{C}_{2}$, long term stability, oxidation resistant

\begin{abstract}
One of the primary factors limiting further research and the commercial use of the two-dimensional (2D) MXene titanium carbide $\left(\mathrm{Ti}_{3} \mathrm{C}_{2}\right)$, as well as MXenes in general, is the rate at which freshly made samples oxidize and degrade when stored as aqueous suspensions. Here, we show that including excess aluminum during synthesis of the $\mathrm{Ti}_{3} \mathrm{AlC}_{2} \mathrm{MAX}$ phase precursor leads to the creation of $\mathrm{Ti}_{3} \mathrm{AlC}_{2}$ grains with improved stoichiometry and crystallinity. $\mathrm{Ti}_{3} \mathrm{C}_{2}$ nanosheets produced from the improved $\mathrm{Ti}_{3} \mathrm{AlC}_{2}$ are of higher quality, as evidenced by their increased resistance to oxidation and an increase in their electrical conductivity to $20,000 \mathrm{~S} / \mathrm{cm}$. Our results indicate that defects created during the synthesis of $\mathrm{Ti}_{3} \mathrm{C}_{2}$ (and by inference, other MXenes) lead to the previously observed instability. We show that by eliminating those defects results in $\mathrm{Ti}_{3} \mathrm{C}_{2}$ that is highly stable in aqueous solutions and in air. Aqueous suspensions of single- to few-layer $\mathrm{Ti}_{3} \mathrm{C}_{2}$ flakes produced from the modified $\mathrm{Ti}_{3} \mathrm{AlC}_{2}$ have a shelf life of over ten months, compared to one to two weeks for $\mathrm{Ti}_{3} \mathrm{C}_{2}$ produced from conventional $\mathrm{Ti}_{3} \mathrm{AlC}_{2}$, even when stored in ambient conditions. Freestanding films made from $\mathrm{Ti}_{3} \mathrm{C}_{2}$ suspensions stored for ten months show minimal decreases in electrical conductivity and negligible oxidation. Oxidation of the improved $\mathrm{Ti}_{3} \mathrm{C}_{2}$ in air initiates at temperatures that are $100-150^{\circ} \mathrm{C}$ higher than conventional $\mathrm{Ti}_{3} \mathrm{C}_{2}$. $\mathrm{Th}$ observed improvements in both the shelf life and properties of $\mathrm{Ti}_{3} \mathrm{C}_{2}$ will facilitate the widespread use of this material.
\end{abstract}

\section{Introduction}

Exfoliation of layered materials into two-dimensional (2D) nanosheets can lead to properties that often differ significantly from their bulk analogs. This has provided new building blocks for nanoscale devices, metamaterials, and composites to meet emerging technological needs. ${ }^{1}$ MXenes are a large family of $2 \mathrm{D}$ transition metal carbides, nitrides, and carbonitrides that have the general formula $\mathrm{M}_{n+1} \mathrm{X}_{n} \mathrm{~T}_{x}$, where $\mathrm{M}$ is an early transition metal, $\mathrm{X}$ is carbon and/or nitrogen, and $\mathrm{n}$ is an integer from 1 to 4 . The $\mathrm{T}_{x}$ represents surface terminations $(=\mathrm{O},-\mathrm{OH}$, and $-\mathrm{F})$ that commonly result from the wet chemical etching methods used to produce MXenes from their MAX phase precursors (A is typically a group 13 or 14 element, e.g. aluminum). More than 30 stoichiometric MXene structures have been synthesized from the more than 100 predicted compositions, and there have also been reports on the creation of solid solution MXenes..$^{2-3}$ MXenes have been utilized in various fields, including energy storage and conversion, electromagnetic interference shielding, nanocomposites, sensors, and biomedical applications. ${ }^{4-5}$

As the scope of MXene research has expanded, so too have studies on improving the quality of MXenes by exploring new synthesis routes and processing methods in order to enhance their performance. ${ }^{6-9}$ MXenes have several significant advantages over graphene and many other conducting nanomaterials: MXenes form stable colloidal solutions without additives or surfactants and they can easily be processed using the cheapest and safest solvent water. However, MXenes are quick to oxidize in aqueous solutions and generally last no more than a few weeks when stored in aqueous media. ${ }^{10-14}$ Some $\mathrm{M}_{2} \mathrm{C}$ MXenes will even degrade within a day. ${ }^{10,15}$ This has prompted many investigations into the mechanisms of MXene degradation in order to prolong their shelf life. ${ }^{10-14,16}$ Recent work has focused on modifying the synthesis of MAX phases, as this can profoundly affect the synthesis, quality, and properties of the resultant MXene. ${ }^{17}$ The common assumption is that phase-pure MAX should lead to the highest quality MXene, and most studies have utilized established MAX phase synthesis procedures that result in the incorporation of minimal amounts of impurities into the sintered product. We report here the surprising result that the phase purity of the as-sintered MAX does not necessarily determine the quality of the resultant MXene. 
a)

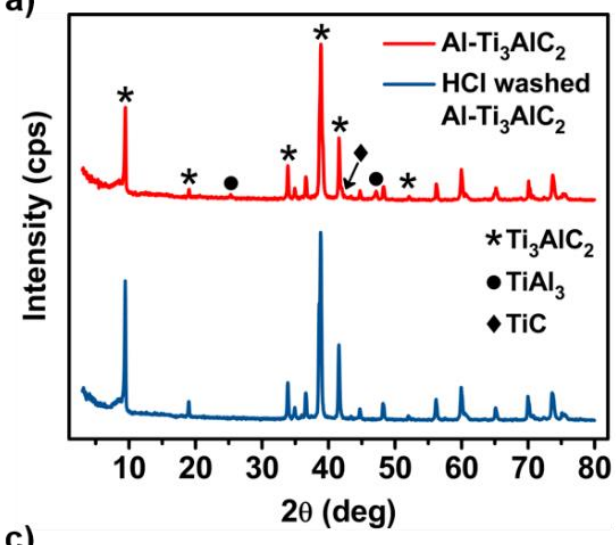

c)

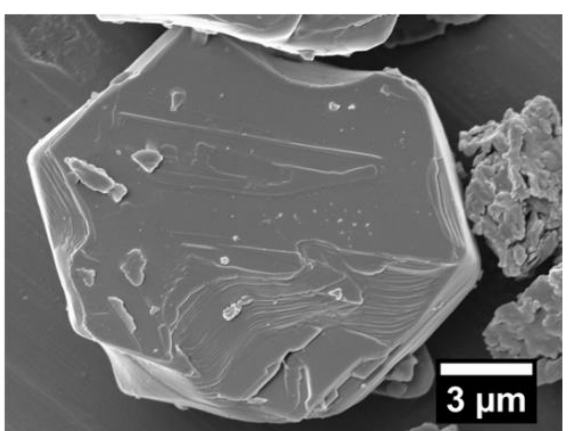

b)

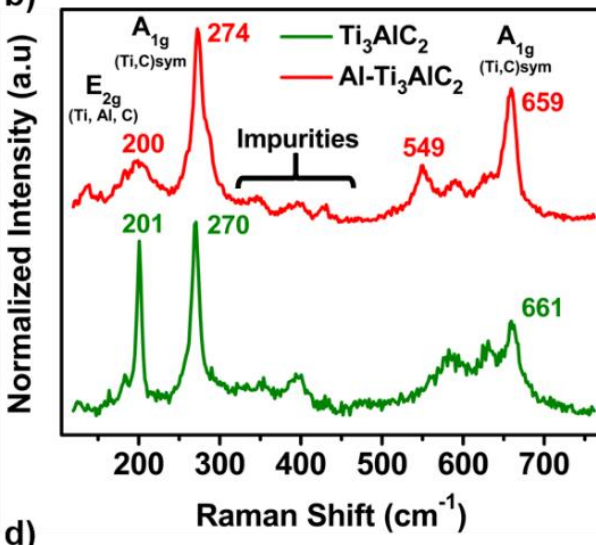

d)

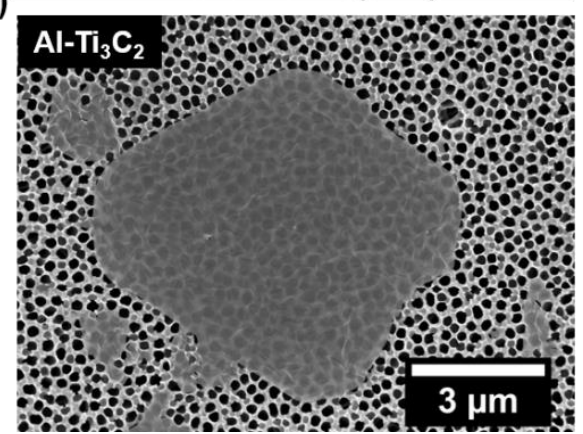

e)

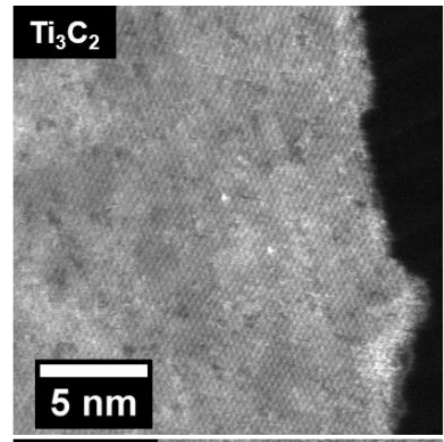

$\mathrm{Al}^{-\mathrm{Ti}_{3} \mathrm{C}_{2}}$

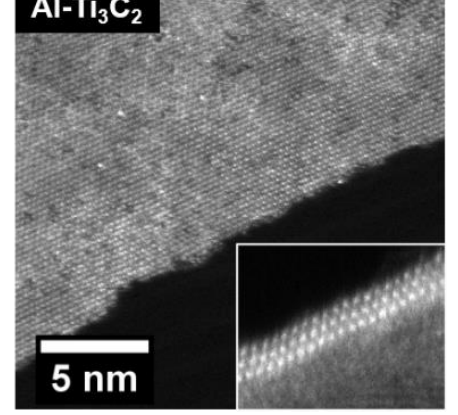

Figure 1. (a) X-ray diffraction patterns of $\mathrm{Al}-\mathrm{Ti}_{3} \mathrm{AlC}_{2}$ before (red) and after (blue) $\mathrm{HCl}$ washing. (b) Polarized Raman spectra of Al$\mathrm{Ti}_{3} \mathrm{AlC}_{2}$ (red, not acid washed) and conventional $\mathrm{Ti}_{3} \mathrm{AlC}_{2}$ (green). (c) Scanning electron microscopy (SEM) image of a hexagonal grain of $\mathrm{HCl}$ washed $\mathrm{Al}-\mathrm{Ti}_{3} \mathrm{AlC}_{2}$. (d) SEM image of a hexagonal, single layer flake of $\mathrm{Al}_{-} \mathrm{Ti}_{3} \mathrm{C}_{2}$ produced via $\mathrm{HF} / \mathrm{HCl}$ etching and $\mathrm{LiCl}$ delamination (supported on an anodic aluminum oxide membrane). (e) High-angle annular dark-field scanning transmission electron microscopy (STEM) images of $\mathrm{Ti}_{3} \mathrm{C}_{2}$ flake edges produced from conventional $\mathrm{Ti}_{3} \mathrm{AlC}_{2}$ (top) and $\mathrm{Al}-\mathrm{Ti}_{3} \mathrm{AlC} \mathrm{C}_{2}(\mathrm{bottom})$. Both types of MAX were $\mathrm{HCl}$ washed prior to etching. Inset in (e) shows an atomic-resolution cross-sectional TEM image from an Al$\mathrm{Ti}_{3} \mathrm{C}_{2}$ flake.

In this study, we included excess aluminum (A-element) during the high-temperature synthesis of the MAX phase $\mathrm{Ti}_{3} \mathrm{AlC}_{2}{ }^{9}$ to create a liquid phase at an early stage of the sintering process. We believe the presence of molten metal during the sintering reaction enhances the diffusion of reactants, resulting in $\mathrm{Ti}_{3} \mathrm{AlC}_{2}$ grains with improved structural ordering and morphology. This MAX phase (which we will refer to as $\mathrm{Al}-\mathrm{Ti}_{3} \mathrm{AlC}_{2}$ ) was then used for the synthesis of high quality $\mathrm{Ti}_{3} \mathrm{C}_{2} \mathrm{~T}_{x}$ nanosheets (subsequently denoted as $\mathrm{Ti}_{3} \mathrm{C}_{2}$ for simplicity). We find that the aqueous $\mathrm{Ti}_{3} \mathrm{C}_{2}$ solutions produced from the $\mathrm{Al}-\mathrm{Ti}_{3} \mathrm{AlC}_{2} \mathrm{MAX}(\mathrm{Al}-$ $\mathrm{Ti}_{3} \mathrm{C}_{2}$ ) have an exceptional shelf life ( $>10$ months at ambient temperature) with only minimal steps taken to protect the MXene. Freestanding films made from fresh $\mathrm{Al}_{-} \mathrm{Ti}_{3} \mathrm{C}_{2}$ solutions have electronic conductivities as high as $20,000 \mathrm{~S} / \mathrm{cm}$. These results represent a significant improvement in the oxidative stability of MXenes and can be expected to significantly impact their incorporation into industrial applications, enhancing their commercial viability.

\section{Results}

$\mathrm{Al}-\mathrm{Ti}_{3} \mathrm{AlC}_{2} \mathrm{MAX}$ was produced by pressureless sintering of a non-stoichiometric mixture of $\mathrm{TiC}, \mathrm{Ti}$, and $\mathrm{Al}$ powders that contained excess $\mathrm{Al}$ (see Experimental Methods section). The as-produced MAX contains intermetallic compounds - namely in the form of $\mathrm{TiAl}_{3}$ - as seen in the X-ray diffraction (XRD) pattern of $\mathrm{Al}-\mathrm{Ti}_{3} \mathrm{AlC}_{2}$ (Fig. 1a, red). The intermetallic impurities cause the body of the block of MAX to have a lustrous, metallic sheen when the sintered block is milled, which is not the case for blocks of $\mathrm{Ti}_{3} \mathrm{AlC}_{2}$ produced using conventional synthesis methods (Fig. S1). ${ }^{9}$ Generally, the use of excess aluminum in the synthesis of MAX phases is known to introduce deleterious impurities into the final sintered product. ${ }^{18-19}$ XRD analysis shows however that these intermetallic impurities can easily be removed by washing the milled $\mathrm{Al}-\mathrm{Ti}_{3} \mathrm{AlC}_{2}$ powder in hydrochloric acid $(\mathrm{HCl})$ at room temperature (Fig. 1a, blue). To better understand how the excess aluminum affects the composition and bonding within the MAX, we further compared the $\mathrm{Al}-\mathrm{Ti}_{3} \mathrm{AlC}_{2}$ with conventional $\mathrm{Ti}_{3} \mathrm{AlC}_{2}$ using Raman spectroscopy. The Raman spectra of $\mathrm{Al}-\mathrm{Ti}_{3} \mathrm{AlC}_{2}$ (red, not acid washed) and conventional $\mathrm{Ti}_{3} \mathrm{AlC}_{2}$ (green, not acid washed) show the presence of $\mathrm{TiC}$ in both samples, along with the MAX phase $\mathrm{Ti}_{3} \mathrm{AlC}_{2}$ (Fig. 1b). The vibrational spectrum of $\mathrm{Ti}_{3} \mathrm{AlC}_{2}$ consists of seven modes: $3 \mathrm{E}_{2 \mathrm{~g}}$ $+2 E_{1 g}+2 A_{1 g}$, where the sharp peak at $201 \mathrm{~cm}^{-1}$ in the spectrum of $\mathrm{Ti}_{3} \mathrm{AlC}_{2}$ (green) is assigned to the $\mathrm{E}_{2 \mathrm{~g}}$ vibration of $\mathrm{Ti}, \mathrm{Al}$ and $\mathrm{C} .{ }^{20}$ This vibration has a larger full width at half

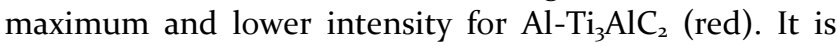
worth noting that this is the only observable vibration that involves $\mathrm{Al}$ atoms. The broadening and diminishing of this peak in $\mathrm{Al}-\mathrm{Ti}_{3} \mathrm{AlC}_{2}$ suggests some structural changes in the 
Al layer. The out-of-plane peaks - $A_{1 g}$ symmetric and asymmetric - are present in both spectra. However, in the case of $\mathrm{Al}-\mathrm{Ti}_{3} \mathrm{AlC}_{2}$, the symmetric peak shifted slightly from 270 to $274 \mathrm{~cm}^{-1}$ and the asymmetric peak shifted from 659 to $661 \mathrm{~cm}^{-1}$. The positions of the corresponding peaks in $\mathrm{Ti}_{3} \mathrm{C}_{2}$ are located at 200 and $723 \mathrm{~cm}^{-1}$, respectively. ${ }^{21}$ The $300-500$ $\mathrm{cm}^{-1}$ region has previously been attributed to impurities, but the exact origin of these peaks has yet to be determined. ${ }^{20}$ There is also a peak at approximately $549 \mathrm{~cm}^{-1}$ which is present only together with the $\mathrm{Ti}_{3} \mathrm{AlC}_{2}$, which suggests that the MAX phase is the origin of this peak. The acid washed $\mathrm{Al}-\mathrm{Ti}_{3} \mathrm{AlC}_{2} \mathrm{MAX}$ also has well-shaped, hexagonal grains. We believe this to be the result of enhanced diffusion of the reactants during the sintering process caused by the presence of molten aluminum (Fig. 1c and Fig. S2).

We etched the $\mathrm{HCl}$ washed $\mathrm{Al}-\mathrm{Ti}_{3} \mathrm{AlC}_{2}$ using a mixture of hydrofluoric and hydrochloric acids $(\mathrm{HF} / \mathrm{HCl}$ etching) and then delaminated the MXene by stirring the etched Al$\mathrm{Ti}_{3} \mathrm{C}_{2}$ in an aqueous solution of $\mathrm{LiCl}$. This procedure yields suspensions of delaminated $\mathrm{Al}_{-}-\mathrm{Ti}_{3} \mathrm{C}_{2}$ flakes that largely retain the shape of the starting $\mathrm{Al}_{-} \mathrm{Ti}_{3} \mathrm{AlC}_{2} \mathrm{MAX}$ particles (Fig. 1d). High-resolution scanning transmission electron microscopy (HRSTEM) images of the edges of conven-

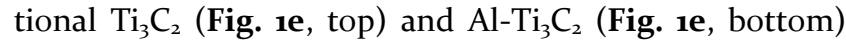
flakes show that the edges of $\mathrm{Al}-\mathrm{Ti}_{3} \mathrm{C}_{2}$ are smoother, without any of the protuberances seen in the conventional $\mathrm{Ti}_{3} \mathrm{C}_{2}$. Images of the basal planes of both flakes look very similar, however (Fig. S3).

One of the characteristic properties of MXenes, and $\mathrm{Ti}_{3} \mathrm{C}_{2}$ in particular, is the high electronic conductivity of films produced from solutions of single- or few-layer MXene flakes. Freestanding films made by vacuum filtering $\mathrm{Al}-$ $\mathrm{Ti}_{3} \mathrm{C}_{2}$ solutions have conductivities ranging from slightly higher than 10,00o $\mathrm{S} / \mathrm{cm}$ up to values exceeding 20,000 $\mathrm{S} / \mathrm{cm}$ (Fig. 2a). It is important to note, that the electronic conductivity of a MXene film depends not only on the quality of the MXene, but also on the film structure and morphology. Features such as flake alignment, film roughness, and interflake distance influence the conductivity of MXene films. The conductivities of the films produced in this study $(>20,000 \mathrm{~S} / \mathrm{cm})$ exceed the values reported in recent years for $\mathrm{Ti}_{3} \mathrm{C}_{2}$ freestanding films and coatings (ranging from 8,000 to $15,000 \mathrm{~S} / \mathrm{cm}$ ). $9,22-24$

The conductivity of the $\mathrm{Al}-\mathrm{Ti}_{3} \mathrm{C}_{2}$ films varies slightly depending on the quantity of water used during the delamination process (Fig. 2a). Since the concentration of the delaminated $\mathrm{Al}-\mathrm{Ti}_{3} \mathrm{C}_{2}$ colloidal solutions is also dependent on the quantity of water used during delamination (Fig. $\mathbf{S}_{4}$ ), it is likely that the highest quality single-layer flakes delaminate first, leading to the highest quality films. However, traces of $\mathrm{LiCl}$ present in the MXene solutions in the initial stages of delamination may also influence the properties of the final films. We find that as the delamination process continues, the remaining $\mathrm{LiCl}$ is removed (Fig. $\mathbf{S}_{\mathbf{5}}$ ).

Thermogravimetric analysis (TGA) of delaminated film and multilayer powder $\mathrm{Ti}_{3} \mathrm{C}_{2}$ samples conducted in air shows that $\mathrm{Al}-\mathrm{Ti}_{3} \mathrm{C}_{2}$ has significantly improved oxidation stability versus $\mathrm{Ti}_{3} \mathrm{C}_{2}$ produced from conventional $\mathrm{Ti}_{3} \mathrm{AlC}_{2}$
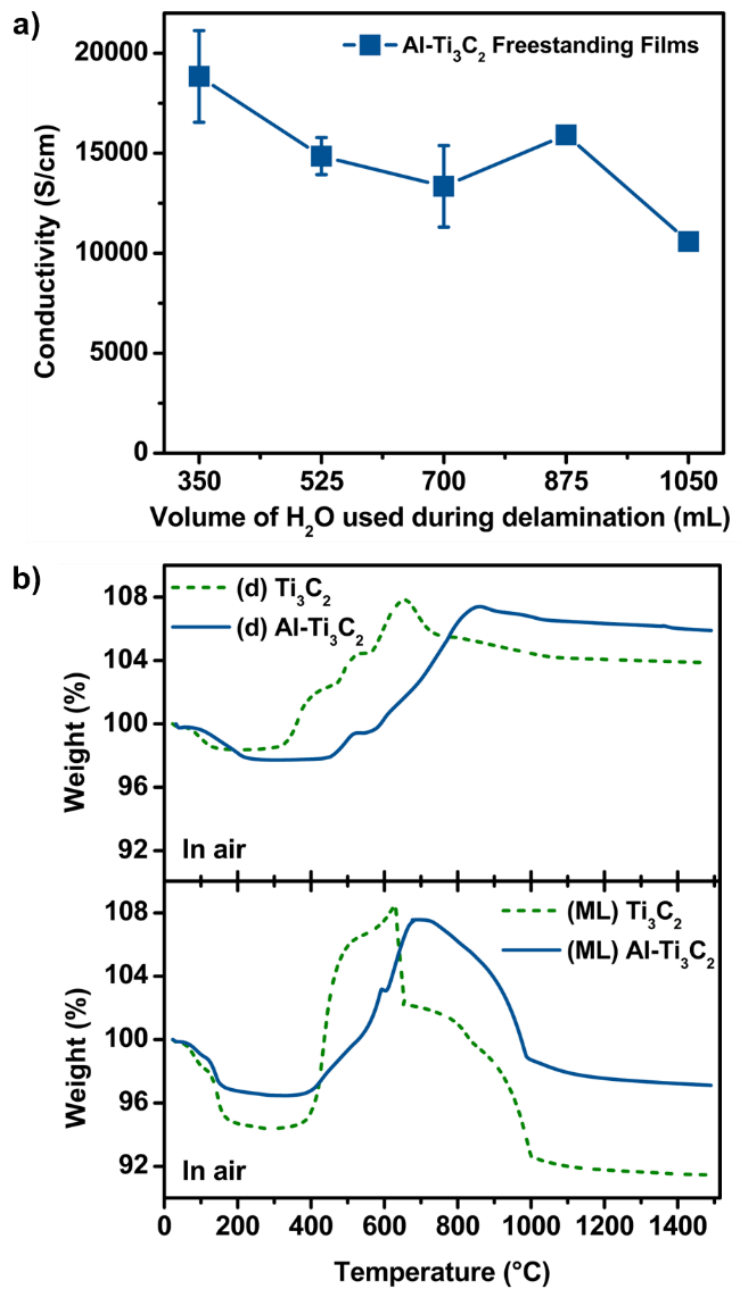

Figure 2. (a) Electronic conductivity of freestanding films

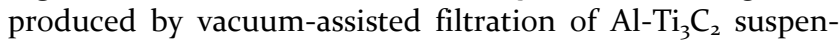
sions at different stages of the delamination process. (b) Thermogravimetric analysis in air for delaminated ((d), top) and multilayer ((ML), bottom) $\mathrm{Ti}_{3} \mathrm{C}_{2}$ produced from $\mathrm{Al}-\mathrm{Ti}_{3} \mathrm{AlC}_{2}$ and conventional $\mathrm{Ti}_{3} \mathrm{AlC}_{2}$. Both types of MAX were washed using $\mathrm{HCl}$ prior to etching.

(Fig. 2b). During the initial stage of heating (below 200 ${ }^{\circ} \mathrm{C}$ ), each sample shows mass loss due to the removal of water that was intercalated between the layers or adsorbed on the surfaces of the MXene samples. Weight gain due to oxidation begins at $\sim 15 \mathrm{O}^{\circ} \mathrm{C}$ higher for the delaminated Al$\mathrm{Ti}_{3} \mathrm{C}_{2}$ versus the conventional $\mathrm{Ti}_{3} \mathrm{C}_{2}$. Oxidation of the Al$\mathrm{Ti}_{3} \mathrm{C}_{2}$ multilayer powder, where the flake edges are exposed and no continuous protective oxide can form, occurs at a much slower rate than the conventional $\mathrm{Ti}_{3} \mathrm{C}_{2}$. This shows that the oxidation stability of MXenes is improved both as aqueous suspensions, and as solid films and powders in air. Moreover, the high-temperature resistance of the delaminated $\mathrm{Al}-\mathrm{Ti}_{3} \mathrm{C}_{2}$ in air is improved by approximately $200{ }^{\circ} \mathrm{C}$ over literature reports, up to over $450^{\circ} \mathrm{C} .25$ This can potentially expand the use of MXenes to applications requiring operation at elevated temperatures in air, such as sensors or electronics operating near hot engines or electrical components. 
a)

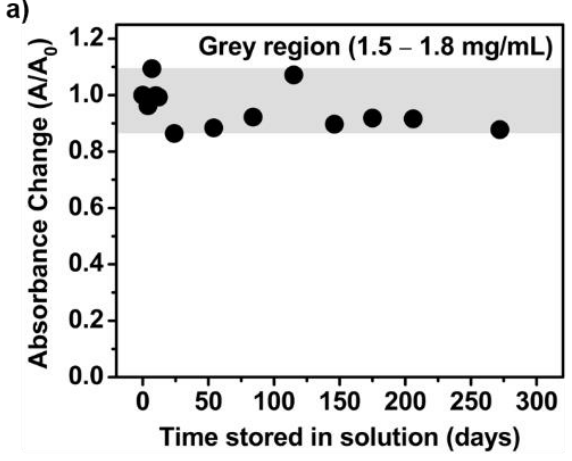

d)

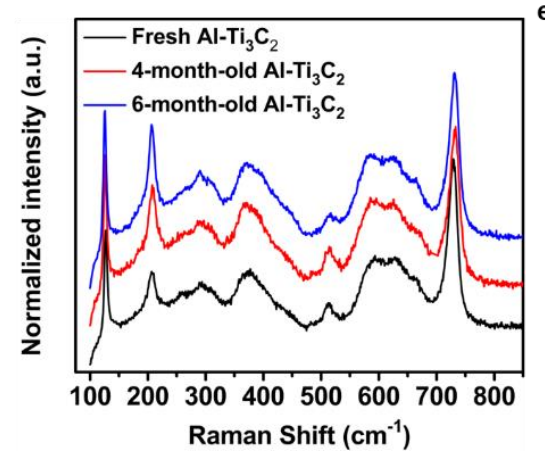

b)

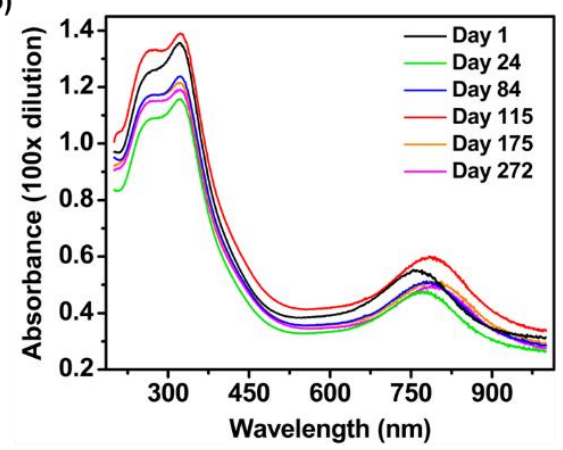

e)

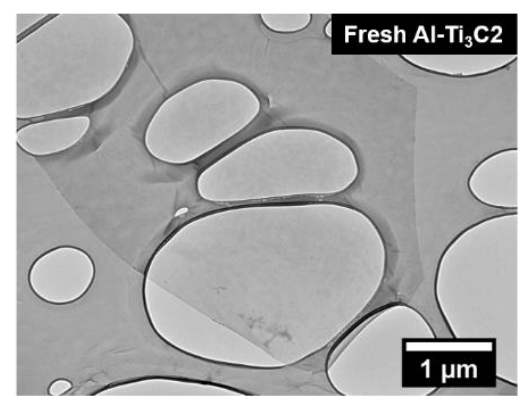

c)

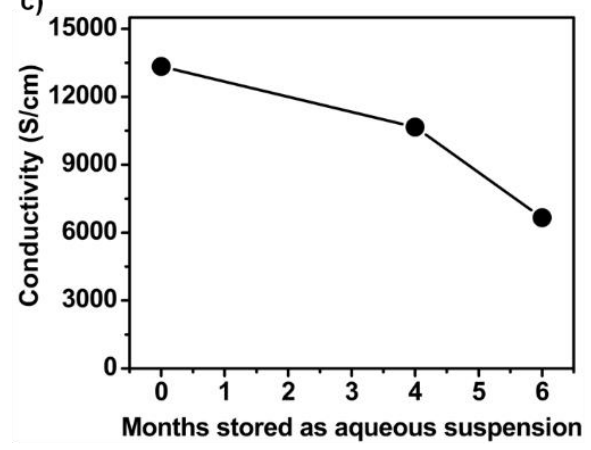

f)

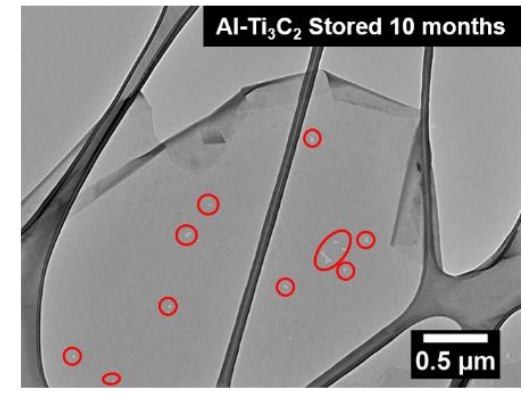

Figure 3. (a) Absorbance changes over time for the stored $\mathrm{Al}_{-} \mathrm{Ti}_{3} \mathrm{C}_{2}$ solution calculated from the UV-vis spectra in (b). The grey region corresponds to suspension concentrations of $1.5-1.8 \mathrm{mg} / \mathrm{mL}$. (b) UV-vis spectra recorded over time for an aqueous Al$\mathrm{Ti}_{3} \mathrm{C}_{2}$ solution stored in ambient conditions. (c) Electronic conductivity of freestanding $\mathrm{Al}^{-} \mathrm{Ti}_{3} \mathrm{C}_{2}$ films made from solutions stored for different periods of time. (d) Raman spectra of films made from solutions stored for different periods of time. TEM images of a fresh $\mathrm{Al}-\mathrm{Ti}_{3} \mathrm{C}_{2}$ flake (e) and an $\mathrm{Al}_{-} \mathrm{Ti}_{3} \mathrm{C}_{2}$ flake from a ten-month-old solution (f). The red circles mark all the observable pinholes in the flake.

The most notable property of the $\mathrm{Al}-\mathrm{Ti}_{3} \mathrm{C}_{2}$ produced from $\mathrm{HCl}$-washed $\mathrm{Ti}_{3} \mathrm{AlC}_{2} \mathrm{MAX}$ is its remarkable shelf life as an aqueous colloidal suspension. To test the long-term stability of the $\mathrm{Al}-\mathrm{Ti}_{3} \mathrm{C}_{2}$ solutions, we took the minimum amount of precautions to protect the $\mathrm{Al}-\mathrm{Ti}_{3} \mathrm{C}_{2}$ flakes, as to simulate the most typical laboratory storage conditions. Delaminated $\mathrm{Al}_{-} \mathrm{Ti}_{3} \mathrm{C}_{2}$ solutions were degassed by bubbling argon through the solutions at the as-produced concentration directly after centrifugation before the solutions were transferred to sealed, argon-filled vials and then stored away from light in a laboratory bench drawer at room temperature. This is a common way of preparing colloidal solutions for shipment or storage that requires no specialized equipment, deep refrigeration, or stabilizing additives. Changes in the suspension's absorbance over time based on UV-Vis measurements recorded periodically during the storage period show that the concentration of the suspension remains relatively unchanged (Fig. 3a). In addition, no noticeable changes in the UV-vis spectra of the stored samples occurred until the 4-month mark (Fig. $3 \mathbf{b}$ ), where a slight red-shift of the $768 \mathrm{~nm}$ peak to $780 \mathrm{~nm}$ occurs. Redshifts of this peak have been shown to be caused by changes in the oxidation state of the $\mathrm{Ti}$ in $\mathrm{Ti}_{3} \mathrm{C}_{2}{ }^{26}$ However, when a film was made from the solution that was stored for 4 months, the conductivity was still over $10,000 \mathrm{~S} / \mathrm{cm}$, well within the range of measurements made from films directly after delamination (Fig. 3c). After 6 months of storage, the UV-vis spectra of the $\mathrm{Al}-\mathrm{Ti}_{3} \mathrm{C}_{2}$ solution still had only a slight red-shift in the $\sim 780 \mathrm{~nm}$ peak, but the conductivity of the film made from the 6-month-old solution dropped to just over $6000 \mathrm{~S} / \mathrm{cm}$. The Raman spectra of the $\mathrm{Al}-\mathrm{Ti}_{3} \mathrm{C}_{2}$ films made from fresh, 4-month-old, and 6month-old solutions are identical. No photoluminescent background is present, meaning there was no titanium oxide formation during storage (Fig. 3d). ${ }^{21}$ Minor oxidation begins after approximately 4 months for these storage conditions, as determined by the decrease in electronic conductivity. Comparison of TEM images of fresh $\mathrm{Al}-\mathrm{Ti}_{3} \mathrm{C}_{2}$ flakes and $\mathrm{Al}-\mathrm{Ti}_{3} \mathrm{C}_{2}$ flakes stored for 10 months exhibit remarkably few pinholes (commonly observed in samples stored for extended periods ${ }^{13}$ (Fig. 3e, f) and very few $\mathrm{TiO}_{2}$ crystals after nearly a year of storage (Fig. S6). From the core level X-ray photoelectron spectra (XPS), there were negligible differences in the chemical environments of $\mathrm{Ti}$, $\mathrm{C}$, and $\mathrm{Al}$ between the $\mathrm{Al}-\mathrm{Ti}_{3} \mathrm{AlC}_{2}$ and the conventional $\mathrm{Ti}_{3} \mathrm{AlC}_{2} \mathrm{MAX}$ phases (Fig. $\mathrm{S}_{\mathbf{7}}$ ). However, close inspection of the $\mathrm{O}$ region reveals that there is less oxygen in the $\mathrm{Al}-$ $\mathrm{Ti}_{3} \mathrm{AlC}_{2}$ (potentially in the form of oxycarbides). This may contribute to the improved oxidation stability of the resulting $\mathrm{Al}-\mathrm{Ti}_{3} \mathrm{C}_{2}$. The straight edges of the $\mathrm{Al}-\mathrm{Ti}_{3} \mathrm{C}_{2}$ flakes show no traces of oxides after being exposed to air for a few days prior to the TEM measurements, which is a sign that the $\mathrm{Al}-\mathrm{Ti}_{3} \mathrm{C}_{2}$ is highly stable. It is known the that oxidation of $\mathrm{Ti}_{3} \mathrm{C}_{2}$ starts from point defects and edges and it was proposed that stabilization of the edges of the flakes by adsorbed species can improve the oxidation stability of $\mathrm{Ti}_{3} \mathrm{C}_{2} \cdot{ }^{27}$ 
Conventionally, aqueous solutions of $\mathrm{Ti}_{3} \mathrm{C}_{2}$ will be completely oxidized after just a few weeks of storage in ambient conditions. ${ }^{10-11,13}$ Therefore, if further steps were taken to

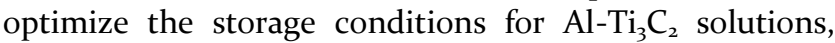
such as storing the samples at temperatures near or below freezing to slow oxidation or by concentrating the $\mathrm{Al}-\mathrm{Ti}_{3} \mathrm{C}_{2}$ solutions to concentrations of tens or even hundreds of $\mathrm{mg} / \mathrm{mL}$ by high speed centrifugation to reduce the total amount of water in the solutions, we speculate that the shelf life of $\mathrm{Al}-\mathrm{Ti}_{3} \mathrm{C}_{2}$ solutions would be increased to years. Recent results show that freezing $\mathrm{Ti}_{3} \mathrm{C}_{2}$ solutions allows for storage for multiple years ${ }^{28}$, however, we can now achieve similar results under ambient conditions with $\mathrm{Al}-\mathrm{Ti}_{3} \mathrm{C}_{2}$. Our current results suggest that the improved oxidation stability of $\mathrm{Al}-\mathrm{Ti}_{3} \mathrm{C}_{2}$ is most likely due to a reduction in the number of defects in the MAX synthesized with excess aluminum, resulting in MXene flakes that should be less defective and have improved Ti:C stoichiometry (Fig. $S_{7}$ e). It has been reported that $\mathrm{Al}$ monovacancies $\left(\mathrm{V}_{\mathrm{Al}}\right)$, $\mathrm{Al}$ divacancies $\left(2 \mathrm{~V}_{\mathrm{Al}-\mathrm{Al}}\right)$, and divacancies composed of $\mathrm{Al}$ and $\mathrm{C}$ atoms $\left(2 \mathrm{~V}_{\mathrm{Al}-\mathrm{C}}\right)$ are the most easily formed vacancies in $\mathrm{Ti}_{3} \mathrm{AlC}_{2} \cdot{ }^{29}$ Therefore, while it may seem counter-intuitive, the presence of excess aluminum should minimize carbon vacancies and reduce the associated loss of $\mathrm{Ti}$ atoms near carbon vacancies after etching, leading to fewer defects in $\mathrm{Ti}_{3} \mathrm{C}_{2}$. More in-depth studies will be needed to understand how the use of excess aluminum, or other molten fluxes ${ }^{30-31}$, during MAX phase synthesis affects the atomic structure, composition, and growth of MAX phases and how these changes can be utilized for the synthesis of high-quality MXene. However, even without a complete understanding of the exact origin of the dramatic improvement in the stability of $\mathrm{Ti}_{3} \mathrm{C}_{2}$, the results presented in this study will allow the MXene community to begin utilizing highly stable MXenes.

In prior work, researchers selecting MAX phase precursors for MXene synthesis were solely concerned with the phase purity of the MAX. Our results show that the optimization of MAX phase synthesis should consider the properties of the resulting MXenes. As of now, the crystallinity and M:X stoichiometric ratio of the MAX appear to be the main factors. Finding optimal precursor ratios and synthesis conditions for non- $\mathrm{Ti}_{3} \mathrm{AlC}_{2} \mathrm{MAX}$ phases that will not produce mixed compositions (i.e., mixed $\mathrm{M}_{3} \mathrm{AlC}_{2}$ and $\mathrm{M}_{2} \mathrm{AlC}$ phases) or introduce impurities that cannot be readily removed will be the key challenges moving forward.

\section{Conclusions}

By modifying the synthesis of $\mathrm{Ti}_{3} \mathrm{AlC}_{2}$ to produce a more stoichiometric MAX phase with improved structure, we have significantly improved the quality of the resulting $\mathrm{Ti}_{3} \mathrm{C}_{2}$ MXene flakes, thereby markedly improving the shelf life and chemical stability of the MXene. Doing so significantly improves both the commercial viability of MXenes and the ease with which MXenes can be studied. Storage of the improved $\mathrm{Ti}_{3} \mathrm{C}_{2}$ in closed vials at room temperature for 10 months with minimal degradation has been demonstrated. Additionally, the improved flake quality resulted in MXene films with higher electronic conductivity, approaching $20,000 \mathrm{~S} / \mathrm{cm}$ - the highest value reported for any solution processable $2 \mathrm{D}$ material reported thus far. The oxidation stability of the MXene in air was also significantly improved, increasing the onset of high-temperature oxidation in air by $\sim 150{ }^{\circ} \mathrm{C}$. We anticipate that this new methodology will be used as a guide to improve the oxidation stability and electronic conductivity of a large variety of carbide MXenes.

\section{Experimental Methods}

\section{Al-Ti ${ }_{3} \mathrm{AlC}_{2}$ MAX Synthesis}

A 2:1:1 (mass ratio) mixture of $\mathrm{TiC}, \mathrm{Ti}$, and $\mathrm{Al}$ powders was ball milled using zirconia balls for $18 \mathrm{~h}$ at $70 \mathrm{rpm}$. A 2:1 mass ratio of zirconia balls to powder mixture was used. The ball milled precursor powder was then packed into an alumina crucible and covered with graphite foil and placed into a tube furnace. The furnace was purged with argon for $30 \mathrm{~min}$ at room temperature. After purging, the precursor powders were heated to $1380{ }^{\circ} \mathrm{C}$ and held for $2 \mathrm{~h}$ under a constant argon flow at $\sim 100 \mathrm{sccm}$. The heating and cooling rates were both $3{ }^{\circ} \mathrm{C} / \mathrm{min}$. The sintered block of $\mathrm{Al}-\mathrm{Ti}_{3} \mathrm{AlC}_{2}$ was then milled using a TiN coated milling bit to produce MAX powder which was subsequently washed using $9 \mathrm{M}$ $\mathrm{HCl}$ (Fisher Scientific, USA). Typically, $500 \mathrm{~mL}$ of $9 \mathrm{M} \mathrm{HCl}$ is sufficient to wash upwards of 50 to $60 \mathrm{~g}$ of $\mathrm{Al}-\mathrm{Ti}_{3} \mathrm{AlC}_{2}$. The MAX was washed until the evolution of gas bubbles from the solution stopped. Four hours is the minimum washing time that has been tested so far. Acid washing of the $\mathrm{Al}-\mathrm{Ti}_{3} \mathrm{AlC}_{2} \mathrm{MAX}$ results in ca. 20-30\% loss of mass (Fig. S1b) which is primarily attributed to the removal of intermetallic impurities. The acid washed MAX was then neutralized by filtering the $\mathrm{Al}-\mathrm{Ti}_{3} \mathrm{AlC}_{2} / \mathrm{HCl}$ mixture though a vacuum filtration unit followed by repeated filtration of DI water through the $\mathrm{Al}-\mathrm{Ti}_{3} \mathrm{AlC}_{2}$ deposit. The pore size of the filter membrane used was $5 \mu \mathrm{m}$. During neutralization of the acid washed $\mathrm{Al}-\mathrm{Ti}_{3} \mathrm{AlC}_{2}$, the acidic supernatant has a deep purple color (Fig. S1c). The neutralized MAX was then dried in a vacuum oven for at least $6 \mathrm{~h}$ at $80^{\circ} \mathrm{C}$. The dried $\mathrm{Al}-\mathrm{Ti}_{3} \mathrm{AlC}_{2}$ was then sieved through a 450 -mesh (32 $\mu \mathrm{m})$ particle sieve. The washed, dried, and sieved Al$\mathrm{Ti}_{3} \mathrm{AlC}_{2}$ was then etched to produce MXene. The same procedure was used to synthesize $\mathrm{Ti}_{3} \mathrm{AlC}_{2}$ with the conventional amount of $\mathrm{Al}$ by using precursor ratios reported previously in the literature. ${ }^{9}$

\section{$\mathrm{Ti}_{3} \mathrm{C}_{2}$ MXene Synthesis}

Typically, $1 \mathrm{~g}$ of $\mathrm{Al}-\mathrm{Ti}_{3} \mathrm{AlC}_{2}$ was mixed with $20 \mathrm{~mL}$ of etchant and stirred at $400 \mathrm{rpm}$ for $24 \mathrm{~h}$ at $35^{\circ} \mathrm{C}$. The etchant was a 6:3:1 mixture (by volume) of $12 \mathrm{M} \mathrm{HCl}$, DI water, and 50 wt.\% HF (Acros Organics, Fair Lawn, NJ, USA). A loosely capped $60 \mathrm{~mL}$ high density polyethylene bottle was used as the etching container. The etched $\mathrm{Al}-\mathrm{Ti}_{3} \mathrm{C}_{2}$ was washed with DI water via repeated centrifugation and decantation cycles until the supernatant reached $\mathrm{pH} \sim 6$ using a $175 \mathrm{~mL}$ centrifuge tube. Once the MXene was neutralized, one more additional wash cycle was performed to ensure the washing process was complete. 5 wash cycles using a single $175 \mathrm{~mL}$ centrifuge tube are typically enough for $1 \mathrm{~g}$ of MAX etched using $20 \mathrm{~mL}$ of etchant. The etched $\mathrm{Al}-\mathrm{Ti}_{3} \mathrm{C}_{2}$ 
multilayer sediment was then dispersed in a $0.5 \mathrm{M}$ solution of $\mathrm{LiCl}$ (typically $50 \mathrm{~mL}$ solution per gram of starting MAX) to start the delamination process. The $\mathrm{MXene} / \mathrm{LiCl}$ suspension was then stirred at $400 \mathrm{rpm}$ for a minimum of $4 \mathrm{~h}$ at room temperature. The MXene/ $\mathrm{LiCl}$ suspension was then washed with DI water via repeated centrifugation and decantation of the supernatant using a $175 \mathrm{~mL}$ centrifuge tube. The first wash cycle always sediments completely after 3 to 5 minutes of centrifugation at $3500 \mathrm{rpm}$. The second wash cycle and onwards were centrifuged for $1 \mathrm{~h}$ at 3500 rpm before the $\mathrm{Ti}_{3} \mathrm{C}_{2}$ supernatants were collected to ensure the MXene solutions were single flake. The quantity and concentration of the delaminated MXene suspensions produced during each cycle of the delamination process is dependent on the quantity of the MAX that was etched and on the size of the centrifuge tubes used during delamination (Fig. S4a). The solution concentrations and yield reported in this study are typical for etching $1 \mathrm{~g}$ of $\mathrm{Al}_{-} \mathrm{Ti}_{3} \mathrm{AlC}_{2}$ in $20 \mathrm{~mL}$ of etchant and using $175 \mathrm{~mL}$ centrifuge tubes for delamination. Large, single-layer $\mathrm{Al}^{-} \mathrm{Ti}_{3} \mathrm{C}_{2}$ flakes $(>25 \mu \mathrm{m}$ in the largest dimension, Fig. $\mathbf{S}_{\mathbf{4}} \mathbf{c}$ ) can be readily obtained using this method, but it must be noted that the flake sizes of the $\mathrm{Al}-\mathrm{Ti}_{3} \mathrm{C}_{2}$ flakes produced are polydisperse, with average flake sizes of 1.3 to $1.6 \mu \mathrm{m}$ (Fig. S4b). If a narrow flake size distribution range is desired, then separation of the MAX phase into fractions with narrow distributions of particle sizes and/or density gradient centrifugation of colloidal solutions of MXene can be employed to isolate flakes of the desired size. ${ }^{32}$ It is important to note that acid washing the $\mathrm{Al}-\mathrm{Ti}_{3} \mathrm{AlC}_{2}$ prior to etching is crucial for achieving high stability suspensions as any residual ions from the intermetallic impurities may cause the suspensions to flocculate (Fig. S8).

\section{Physical Characterization}

Conductivity measurements were performed using a four-point probe with $1 \mathrm{~mm}$ probe separation (Jandel Engineering Ltd., Bedfordshire, UK) on freestanding MXene films made by vacuum-assisted filtration of delaminated single flake MXene solutions. The measured sheet resistances of the films were converted into conductivity by using the thickness of the films taken from SEM images of the film cross sections. UV-Vis spectra were recorded using an Evolution 201 spectrometer (Thermo Scientific, MA, USA) with a $10 \mathrm{~mm}$ optical path length cuvette and scanning from 200 to $1000 \mathrm{~nm}$, where the absorbance was measured for samples at 1oox dilution. Particle size analysis was performed using a Malvern Panalytical Zetasizer Nano ZS in a polystyrene cuvette. Three measurements were recorded, and the average intensity distribution was reported. For the long-term storage tests, solutions from the 3rd delamination cycle $(700 \mathrm{~mL})$ were used since any excess $\mathrm{LiCl}$ would have been removed by that cycle. The concentrations of the stored $\mathrm{Ti}_{3} \mathrm{C}_{2}$ samples were calculated by measuring the absorbance changes of the samples over time versus the absorbance of the $\mathrm{Ti}_{3} \mathrm{C}_{2}$ samples at the initial time of storage, normalized at $264 \mathrm{~nm}$. Raman spectra were recorded using a reflection mode Renishaw InVia spectrometer (Renishaw plc, Gloucestershire, UK) equipped with $20 x$ $(\mathrm{NA}=0.4)$ and $63 x(\mathrm{NA}=0.7)$ objectives and a diffraction- based room-temperature CCD spectrometer. For MAX phase analysis, we used an $\mathrm{Ar}+$ laser (488 and $514 \mathrm{~nm}$ emissions) and an 1800 line $/ \mathrm{mm}$ grating, and for analysis of MXene we used a diode $(785 \mathrm{~nm}$ ) laser with a 1200 line $/ \mathrm{mm}$ diffraction grating. The power of the lasers was within the $\sim 0.3-1 \mathrm{~mW}$ range. Transmission electron microscopy (TEM) and scanning transmission electron microscopy (STEM) images were taken using a JEOL JEM210o and JEOL NEOARM (JEOL Ltd., JP), respectively, at an operating voltage of $200 \mathrm{kV}$. The colloid solution containing delaminated $\mathrm{Al}-\mathrm{Ti}_{3} \mathrm{C}_{2}$ flakes was drop-cast onto lacey carbon films on copper TEM grids (Electron Microscopy Sciences, PA, USA). Thermal analysis (TGA) measurements were conducted using an SDT 650 thermal analysis system (TA Instruments, New Castle, DE, USA). Samples were heated at $10^{\circ} \mathrm{C} / \mathrm{min}$ from room temperature to $1500{ }^{\circ} \mathrm{C}$ under constant flow of compressed dry air at $100 \mathrm{sccm}$. Samples for thermal analysis were equilibrated overnight in vials exposed to ambient atmosphere.

\section{ASSOCIATED CONTENT}

Supporting Information is available free of charge on the ACS Publications website at DOI: to be filled in by editorial team

\section{AUTHOR INFORMATION}

\section{Corresponding Author}

*gogotsi@drexel.edu

\section{Author Contributions}

T. S. M. conducted synthesis and SEM characterization, K. M. conducted optical characterization, A. G. and A. C. F. conducted TEM studies, A. S. performed Raman analysis, M. A. performed XPS, TGA, and XRD analysis, K. H. assisted in interpreting XPS and TGA results, E. A. S. oversaw TEM analysis and Y. G. supervised the entire study. The manuscript was written through contributions of all authors and all authors have given approval to the final version of the manuscript.

\section{ACKNOWLEDGMENTS}

The synthesis and characterization of MAX and MXene materials performed in this study was supported by the Fluid Interface Reactions, Structures \& Transport (FIRST) Center, an Energy Frontier Research Center funded by the US Department of Energy, Office of Science, Office of Basic Energy Sciences. M. A. was supported by the National Science Foundation Graduate Research Fellowship under Grant \#DGE-1646737. A. C. F. and E. A. S. would like to acknowledge the Vagelos Institute for Energy Science and Technology at the University of Pennsylvania for a graduate fellowship. This work was performed in part at the Singh Center for Nanotechnology at the University of Pennsylvania, a member of the National Nanotechnology Coordinated Infrastructure (NNCI) network, which is supported by the National Science Foundation (Grant NNCI-1542153). Additional support for the electron microscopy facilities was provided by the supported by NSF through the University of Pennsylvania Materials Research Science and Engineering Center (MRSEC) (DMR-1720530). Any opinions, findings, and conclusions or recommendations expressed in this material are those of the author(s) and do not necessarily reflect the views of the National Science Foundation. 


\section{REFERENCES}

1. Nicolosi, V.; Chhowalla, M.; Kanatzidis, M. G.; Strano, M. S.; Coleman, J. N., Liquid Exfoliation of Layered Materials. Science 2013, 340 (6139), 1226419.

2. Anasori, B.; Gogotsi, Y., $2 D$ Metal Carbides and Nitrides (MXenes): Structure, Properties and Applications. Springer, Cham: 2019.

3. Han, M.; Shuck, C. E.; Rakhmanov, R.; Parchment, D.; Anasori, B.; Koo, C. M.; Friedman, G.; Gogotsi, Y., Beyond $\mathrm{Ti}_{3} \mathrm{C}_{2} \mathrm{~T}_{x}$ : MXenes for Electromagnetic Interference Shielding. ACS Nano 2020, 14 (4), 5008-5016.

4. Anasori, B.; Lukatskaya, M. R.; Gogotsi, Y., 2D metal carbides and nitrides (MXenes) for energy storage. Nature Reviews Materials 2017, 2 (2), 16098.

5. Gogotsi, Y.; Anasori, B., The Rise of MXenes. ACS Nano 2019, 13 (8), 8491-8494.

6. Anayee, M.; Kurra, N.; Alhabeb, M.; Seredych, M. Hedhili, M. N.; Emwas, A.-H.; Alshareef, H. N.; Anasori, B.; Gogotsi, Y., Role of acid mixtures etching on the surface chemistry and sodium ion storage in $\mathrm{Ti}_{3} \mathrm{C}_{2} \mathrm{~T}_{x}$ MXene. Chemical Communications 2020, 56, 6090-6093.

7. Hantanasirisakul, K.; Alhabeb, M.; Lipatov, A.; Maleski, K.; Anasori, B.; Salles, P.; Ieosakulrat, C.; Pakawatpanurut, P.; Sinitskii, A.; May, S. J.; Gogotsi, Y., Effects of Synthesis and Processing on Optoelectronic Properties of Titanium Carbonitride MXene. Chemistry of Materials 2019, 31 (8), 2941-2951.

8. Li, Y.; Shao, H.; Lin, Z.; Lu, J.; Liu, L.; Duployer, B.; Persson, P. O. Å.; Eklund, P.; Hultman, L.; Li, M.; Chen, K.; Zha, X.-H.; Du, S.; Rozier, P.; Chai, Z.; Raymundo-Piñero, E.; Taberna P.-L.; Simon, P.; Huang, Q., A general Lewis acidic etching route for preparing MXenes with enhanced electrochemical performance in non-aqueous electrolyte. Nature Materials 2020, 19, 894-899.

9. Alhabeb, M.; Maleski, K.; Anasori, B.; Lelyukh, P.; Clark, L.; Sin, S.; Gogotsi, Y., Guidelines for Synthesis and Processing of Two-Dimensional Titanium Carbide $\left(\mathrm{Ti}_{3} \mathrm{C}_{2} \mathrm{~T}_{x}\right.$ MXene). Chemistry of Materials 2017, 29 (18), 7633-7644.

10. Huang, S.; Mochalin, V. N., Hydrolysis of 2D TransitionMetal Carbides (MXenes) in Colloidal Solutions. Inorganic Chemistry 2019, 58 (3), 1958-1966.

11. Chae, Y.; Kim, S. J.; Cho, S.-Y.; Choi, J.; Maleski, K.; Lee, B.-J.; Jung, H.-T.; Gogotsi, Y.; Lee, Y.; Ahn, C. W., An investigation into the factors governing the oxidation of two-dimensional $\mathrm{Ti}_{3} \mathrm{C}_{2}$ MXene. Nanoscale 2019, 11 (17), 8387-8393.

12. Lipatov, A.; Alhabeb, M.; Lukatskaya, M. R.; Boson, A.; Gogotsi, Y.; Sinitskii, A., Effect of Synthesis on Quality, Electronic Properties and Environmental Stability of Individual Monolayer $\mathrm{Ti}_{3} \mathrm{C}_{2}$ MXene Flakes. Advanced Electronic Materials 2016, 2 (12), 1600255 .

13. Zhang, C. J.; Pinilla, S.; McEvoy, N.; Cullen, C. P.; Anasori, B.; Long, E.; Park, S.-H.; Seral-Ascaso, A.; Shmeliov, A.; Krishnan, D.; Morant, C.; Liu, X.; Duesberg, G. S.; Gogotsi, Y.; Nicolosi, V., Oxidation Stability of Colloidal Two-Dimensional Titanium Carbides (MXenes). Chemistry of Materials 2017, 29 (11), 48484856 .

14. Zhao, X.; Vashisth, A.; Prehn, E.; Sun, W.; Shah, S. A.; Habib, T.; Chen, Y.; Tan, Z.; Lutkenhaus, J. L.; Radovic, M.; Green, M. J., Antioxidants Unlock Shelf-Stable $\mathrm{Ti}_{3} \mathrm{C}_{2} \mathrm{~T}_{x}$ (MXene) Nanosheet Dispersions. Matter 2019, 1 (2), 513-526.

15. Huang, S.; Mochalin, V. N., Understanding Chemistry of Two-Dimensional Transition Metal Carbides and Carbonitrides (MXenes) with Gas Analysis. ACS Nano 2020. https://doi.org/10.1021/acsnano.oco1157

16. Habib, T.; Zhao, X.; Shah, S. A.; Chen, Y.; Sun, W.; An, H.; Lutkenhaus, J. L.; Radovic, M.; Green, M. J., Oxidation stability of $\mathrm{Ti}_{3} \mathrm{C}_{2} \mathrm{~T}_{x}$ MXene nanosheets in solvents and composite films. $n p j$ $2 D$ Materials and Applications 2019, 3 (1), 8.

17. Shuck, C. E.; Han, M.; Maleski, K.; Hantanasirisakul, K.; Kim, S. J.; Choi, J.; Reil, W. E. B.; Gogotsi, Y., Effect of $\mathrm{Ti}_{3} \mathrm{AlC}_{2} \mathrm{MAX}$ Phase on Structure and Properties of Resultant $\mathrm{Ti}_{3} \mathrm{C}_{2} \mathrm{~T}_{x}$ MXene. ACS Applied Nano Materials 2019, 2 (6), 3368-3376.

18. Etzkorn, J.; Ade, M.; Hillebrecht, H., $\mathrm{Ta}_{3} \mathrm{AlC}_{2}$ and $\mathrm{Ta}_{4} \mathrm{AlC}_{3}$ - Single-Crystal Investigations of Two New Ternary Carbides of Tantalum Synthesized by the Molten Metal Technique. Inorganic Chemistry 2007, 46 (4), 1410-1418.

19. Tzenov, N. V.; Barsoum, M. W., Synthesis and Characterization of $\mathrm{Ti}_{3} \mathrm{AlC}_{2}$. Journal of the American Ceramic Society 2000, 83 (4), 825-832.

20. $\quad$ Presser, V.; Naguib, M.; Chaput, L.; Togo, A.; Hug, G.; Barsoum, M. W., First-order Raman scattering of the MAX phases: $\mathrm{Ti}_{2} \mathrm{AlN}, \mathrm{Ti}_{2} \mathrm{AlC}_{\mathrm{0.5}} \mathrm{N}_{\mathrm{o.5}}, \mathrm{Ti}_{2} \mathrm{AlC},\left(\mathrm{Ti}_{\mathrm{o} .5} \mathrm{~V}_{0.5}\right)_{2} \mathrm{AlC}, \mathrm{V}_{2} \mathrm{AlC}, \mathrm{Ti}_{3} \mathrm{AlC}_{2}$, and $\mathrm{Ti}_{3} \mathrm{GeC}_{2}$. Journal of Raman Spectroscopy 2012, 43 (1), 168-172.

21. Sarycheva, A.; Gogotsi, Y., Raman Spectroscopy Analysis of the Structure and Surface Chemistry of $\mathrm{Ti}_{3} \mathrm{C}_{2} \mathrm{~T}_{x}$ MXene. Chemistry of Materials 2020, 32 (8), 3480-3488.

22. Zhang, C.; Anasori, B.; Seral-Ascaso, A.; Park, S.-H. McEvoy, N.; Shmeliov, A.; Duesberg, G. S.; Coleman, J. N.; Gogotsi, Y.; Nicolosi, V., Transparent, Flexible, and Conductive 2D Titanium Carbide (MXene) Films with High Volumetric Capacitance. Advanced Materials 2017, 29 (36), 1702678.

23. Zhang, J.; Kong, N.; Uzun, S.; Levitt, A.; Seyedin, S.; Lynch, P. A.; Qin, S.; Han, M.; Yang, W.; Liu, J.; Wang, X.; Gogotsi, Y.; Razal, J. M., Scalable Manufacturing of Free-Standing, Strong $\mathrm{Ti}_{3} \mathrm{C}_{2} \mathrm{~T}_{x}$ MXene Films with Outstanding Conductivity. Advanced Materials 2020, 32 (23), 2001093.

24. Mirkhani, S. A.; Shayesteh Zeraati, A.; Aliabadian, E. Naguib, M.; Sundararaj, U., High Dielectric Constant and Low Dielectric Loss via Poly(vinyl alcohol) $/ \mathrm{Ti}_{3} \mathrm{C}_{2} \mathrm{~T}_{x}$ MXene Nanocomposites. ACS Applied Materials E Interfaces 2019, 11 (20), 1859918608.

25. Li, Z.; Wang, L.; Sun, D.; Zhang, Y.; Liu, B.; Hu, Q.; Zhou, A., Synthesis and thermal stability of two-dimensional carbide MXene $\mathrm{Ti}_{3} \mathrm{C}_{2}$. Materials Science and Engineering: B 2015, 191, 33-40.

26. Salles, P.; Pinto, D.; Hantanasirisakul, K.; Maleski, K.; Shuck, C. E.; Gogotsi, Y., Electrochromic Effect in Titanium Carbide MXene Thin Films Produced by Dip-Coating. Advanced Functional Materials 2019, 29 (17), 1809223.

27. Natu, V.; Sokol, M.; Verger, L.; Barsoum, M. W., Effect of Edge Charges on Stability and Aggregation of $\mathrm{Ti}_{3} \mathrm{C}_{2} \mathrm{~T}_{z}$ MXene Colloidal Suspensions. The Journal of Physical Chemistry $C$ 2018, 122 (48), 27745-27753

28. Zhang, J.; Kong, N.; Hegh, D.; Usman, K. A. S.; Guan, G.; Qin, S.; Jurewicz, I.; Yang, W.; Razal, J. M., Freezing Titanium Carbide Aqueous Dispersions for Ultra-long-term Storage. ACS Applied Materials E Interfaces 2020, 12 (30), 34032-34040.

29. $\quad$ Meng, Z.; Wang, C.; Liu, J.; Wang, Y.; Zhu, X.; Yang, L.; Huang, L., New insight into the interaction between divacancy and $\mathrm{H} / \mathrm{He}$ impurity in $\mathrm{Ti}_{3} \mathrm{AlC}_{2}$ using first-principles studies. Physical Chemistry Chemical Physics 2020. https://doi.org/10.1039/DoCPo2982C

3o. Etzkorn, J.; Ade, M.; Hillebrecht, H., $\mathrm{V}_{2} \mathrm{AlC}, \mathrm{V}_{4} \mathrm{AlC}_{3-\mathrm{x}}(\mathrm{x}$ $\approx 0.31$ ), and $\mathrm{V}_{12} \mathrm{Al}_{3} \mathrm{C}_{8}$ : Synthesis, Crystal Growth, Structure, and Superstructure. Inorganic Chemistry 2007, 46 (18), 7646-7653.

31. Wang, D.; Si, J.; Lin, S.; Zhang, R.; Huang, Y.; Yang, J.; Lu, W.; Zhu, X.; Sun, Y., Achieving Macroscopic $\mathrm{V}_{4} \mathrm{C}_{3} \mathrm{~T}_{x}$ MXene by Selectively Etching $\mathrm{Al}$ from $\mathrm{V}_{4} \mathrm{AlC}_{3}$ Single Crystals. Inorganic Chemistry 2020, 59 (5), 3239-3248.

32. Maleski, K.; Ren, C. E.; Zhao, M.-Q.; Anasori, B.; Gogotsi, Y., Size-Dependent Physical and Electrochemical Properties of Two-Dimensional MXene Flakes. ACS Applied Materials $\mathcal{E}$ Interfaces 2018, 10 (29), 24491-24498. 
For Table of Contents Only

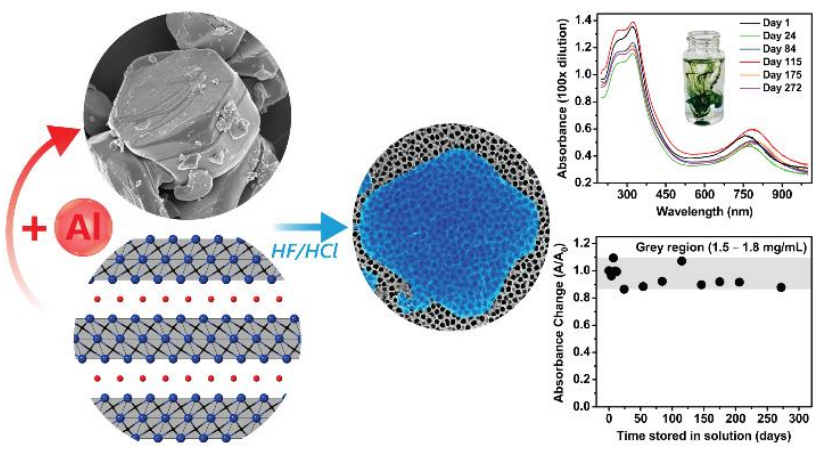

